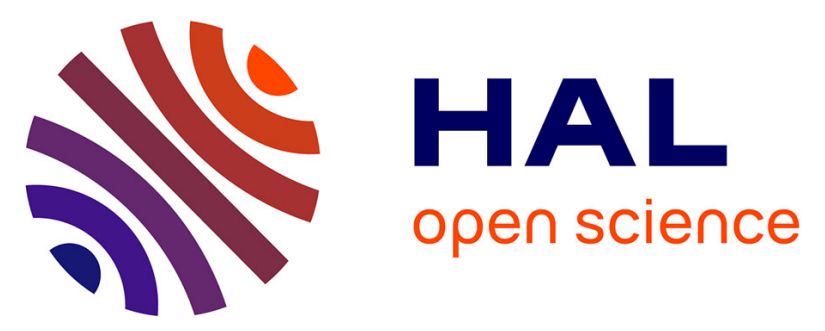

\title{
Relation between morphology and conductivity in TiO2 nanotube arrays: an electrochemical impedance spectrometric investigation
}

\author{
Peng Pu, Hubert Cachet, Edgard Ngaboyamahina, Eliane Sutter
}

\section{- To cite this version:}

Peng Pu, Hubert Cachet, Edgard Ngaboyamahina, Eliane Sutter. Relation between morphology and conductivity in $\mathrm{TiO} 2$ nanotube arrays: an electrochemical impedance spectrometric investigation. Journal of Solid State Electrochemistry, 2013, 17, pp.817-828. 10.1007/s10008-012-1931-0 . hal00785963

\section{HAL Id: hal-00785963 \\ https://hal.sorbonne-universite.fr/hal-00785963}

Submitted on 7 Feb 2013

HAL is a multi-disciplinary open access archive for the deposit and dissemination of scientific research documents, whether they are published or not. The documents may come from teaching and research institutions in France or abroad, or from public or private research centers.
L'archive ouverte pluridisciplinaire HAL, est destinée au dépôt et à la diffusion de documents scientifiques de niveau recherche, publiés ou non, émanant des établissements d'enseignement et de recherche français ou étrangers, des laboratoires publics ou privés. 


\title{
Relation between morphology and conductivity in $\mathrm{TiO}_{2}$ nanotube arrays. An electrochemical impedance spectrometric investigation.
}

\author{
P. Pu, H. Cachet, E. Ngaboyamahina, E.M.M Sutter* . \\ CNRS, UPR15, Laboratoire Interfaces et Systèmes Electrochimiques, F-75005 Paris, France \\ UPMC Univ Paris 06, UPR15, LISE, 4 place Jussieu, F-75005 Paris, France
}

\begin{abstract}
Two types of $\mathrm{TiO}_{2}$ nano-tubular arrays were obtained by anodization of a titanium foil, in two different solutions containing fluoride ions. For the first type which has rough tube walls, impedance measurements in the dark showed the presence of a localised surface state which was related to adsorbed molecular water. Under UV illumination this adsorbed molecular water was photo-dissociated. Moreover an increase of two orders of magnitude for the limiting capacitance of the space charge layer was observed, simultaneously with the disappearance of the localised state and with a 100 times increase of the carrier density associated with hydrogen insertion. The second type of layer was characterized by smoother tube walls, a high doping level $\left(10^{20} \mathrm{~cm}^{-3}\right)$ in the dark, a lack of localised states, and no long-lasting photo induced effect. In this case, the width of the space charge layer became rapidly higher than the half thickness of the tube walls, when the applied potential increased. Therefore, the walls were progressively depleted under anodic polarization, passing from a situation where the tubes were totally active in the cathodic range towards a situation where the contribution of the tube walls could be neglected.
\end{abstract}

\footnotetext{
* To whom correspondence should be addressed: phone 331442741 68; fax: 33144274074.

E-mail: eliane-sutter@upmc.fr
} 


\section{Introduction}

Since Gong and co-workers successfully fabricated the first generation of $\mathrm{TiO}_{2}$ nanotubular arrays by anodizing a titanium foil in a fluoride based electrolyte [1], this highly ordered and vertically oriented morphology keeps attracting the attention due to its particular properties [2-4]: a large internal surface, direct transport pathways and the possibility to form surface states that influence the interfacial electron-transfer process. The outstanding charge transport of $\mathrm{TiO}_{2}$ nanotubes enables various advanced applications, such as in sensors [5-7], dye sensitized solar cells [8-10], photocatalysis [11-13] and water photo-electrolysis [14-16].

$\mathrm{TiO}_{2}$ nanotubes can be produced by several methods: using templates [17, 18], via hydrothermal techniques $[19,20]$ or by anodization of titanium in a florid containing electrolyte [21-24]. This latter process allows a better control over the nanotube characteristics (length, tubes diameters, walls thickness etc..). For example, the tube length and the pore size depend on the anodization time and the applied potential. The aspect ratio, which is defined as the nanotube length-to-outer diameter ratio, can be controlled from 10 to 20000 according to the chosen conditions. The type of electrolyte determines the architecture: from interconnected tubes to packed tubes [25-27] and also has an impact on the nanotube roughness. This latter influences both the behaviour of the surface in relation to adsorption and the distribution of active sites such as oxygen vacancies or five coordinated 5c-Ti [28]. Besides, the high roughness increases the disorder degree at the surface. As a result, adsorption of some species, such as molecular water, is favoured [29].

In opposition to the compact layer, the nanotubular layer is not a flat capacitor. The voltage drop takes place inside the nanotube walls and the space charge region spreads circularly over a few nanometers [30]. As the support of band bending, the wall thickness is a key parameter for electron transport. If the half wall thickness is significantly greater than the width of the space charge layer, there remains a neutral region for the charge transport in the middle of the wall. However, if the half wall thickness is shorter than the width of the space charge layer, the depletion zone goes through the wall and the nanotube remains inactivate in the dark. 
In this work, two different architectures of $\mathrm{TiO}_{2}$ nanotubes are characterized by electrochemical impedance spectroscopy. A geometric model proposed in [2] is used to study the behaviour of the space charge layer and of the surface states in the dark. The photo induced effect will also be discussed.

\section{Experimental}

Synthesis of $\mathrm{TiO}_{2}$ nanotubular films

Two kinds of $\mathrm{TiO}_{2}$ nanotube array films were made in the same conditions by anodic oxidation of a titanium rod ( $2 \mathrm{~mm}$ thickness, $15 \mathrm{~mm}$ diameter, $99.6 \%$ purity), but in two different electrolytes: the first one noted $\mathrm{TiO}_{2}-\mathrm{NT}(\mathrm{TB})$ in a $0.27 \mathrm{~mol} \mathrm{~L}^{-1}$ tetrabutylammonium fluoride solution in formamide containing 3\% deionized water [25] and the second one noted $\mathrm{TiO}_{2}-$ $N T(E G)$ in a $3 \mathrm{wt} \% \mathrm{NH}_{4} \mathrm{~F}$ solution in ethylene glycol containing 2 vol\% deionized water [26]. The oxidation potential was kept constant at $20 \mathrm{~V}$ during 45 minutes.

As-anodized samples were first thoroughly rinsed with ethanol, then with water, followed by ultrasonication cleaning in ethanol. Finally the samples were dried under nitrogen then annealed in air at $525{ }^{\circ} \mathrm{C}$ during 2 hours with a ramp-up and ramp-down rate of $1{ }^{\circ} \mathrm{C} / \mathrm{min}$. Raman spectroscopy analyses showed that after annealing, anatase is the main constituent of the two layers.

Electrochemical impedance measurements

Electrochemical measurements were performed at room temperature in a standard threeelectrode cell. All potentials were measured against and referred to a saturated calomel reference electrode (SCE), with a platinum plate counter electrode. An electrochemical interface (Solartron SI 1287) and a frequency response analyser (Solartron 1250) were used for impedance measurements which were performed in potentiostatic conditions (between $0.1 \mathrm{~V} / \mathrm{SCE}$ and -0.8 $\mathrm{V} / \mathrm{SCE}$ in $100 \mathrm{mV}$ steps), over frequencies ranging from $0.1 \mathrm{~Hz}$ to $65 \mathrm{kHz}$, using a $10 \mathrm{mV}$ sinusoidal potential modulation. Side and back surfaces of the working electrode were covered with an insulating resin (Araldite). For electrical contact, a conductive copper wire was attached 
on the backside of the titanium substrate using conductive silver adhesive, after removing the passive layer. Samples were finally cleaned as mentioned previously. The geometric flat surface of the samples exposed to the electrolyte was $0.64 \mathrm{~cm}^{2}\left(S_{\mathrm{fl}}\right)$.

All measurements were carried out in $1 \mathrm{~mol} \mathrm{~L}^{-1}$ deaerated $\mathrm{Na}_{2} \mathrm{SO}_{4}$ solution (deionised water (Millipore) and $\mathrm{Na}_{2} \mathrm{SO}_{4} \cdot 3 \mathrm{H}_{2} \mathrm{O}$ (PROLABO)). Before each experiment, oxygen was removed from the solution through $\mathrm{N}_{2}$ bubbling during 1 hour (purity $99.995 \%$ ).

Impedance data were fitted with ZSimpWim ${ }^{\mathrm{TM}}$ software (Princeton Applied Research). A $125 \mathrm{~W}$ mercury vapour lamp (HPR $125 \mathrm{~W}$ (Philips)) was used as the UV light source (wavelength range 300-400 $\mathrm{nm}$ ).

Protocol for impedance measurements in potentiostatic conditions.

EIS measurements were first performed in the dark starting from $-0.8 \mathrm{~V}$. The applied potential value was increased in $0.1 \mathrm{~V}$ steps, held at the new value during 2 minutes, before performing other impedance measurements. The sample was exposed to UV light during three hours, then the light was switched off and the electrode was stored during one hour in the darkness. Impedance measurements were then performed in the dark again at various applied potentials as stated previously.

\section{Results}

SEM pictures of the two types of layers

In Fig. 1a, the nanotubular layer obtained in $0.27 \mathrm{~mol} \mathrm{~L}^{-1}$ tetrabutylammonium fluoride in formamide is made of open tubes with an average values of about $50 \mathrm{~nm}$ for the inner diameter and $100 \mathrm{~nm}$ for the outer diameter. The tube diameter slightly increases from top to bottom of the layer. The tubes are spaced from each other, but the individual tubes are connected via rings on the sidewalls of the tubes. The thickness of the layer is about $1 \mu \mathrm{m}$. The nanotubes obtained in the $\mathrm{NH}_{4} \mathrm{~F}$ solution in ethylene glycol show much smoother tube walls. They are well-oriented over the substrate, and are about $1.2 \mu \mathrm{m}$ long, with $40 \mathrm{~nm}$ for the inner diameter and $60 \mathrm{~nm}$ for the outer diameter (Fig. 1b). 
Geometric model

The geometric parameters of these two types of nanotubes could be obtained by the ideal geometric model published in previous papers [2, 31]: a regular array of tubes included in a hexagonal mesh was taken as geometric model assuming an ideal regular network of identical and equally spaced nanotubes (Fig. 2a). Each tube is considered to be a hollow cylinder of internal radius $R_{1}$ and axial symmetry. $R_{2}$ represents the distance between the tube centre and the centre of the tube wall (Fig. 2b). The thickness of the wall is defined by:

$$
w=2\left(R_{2}-R_{1}\right)
$$

The length of the nanotubes $(h)$ and the distance $(y)$ between two tubes are considered to be constant. The surface solid fraction $\varphi$, was defined as the ratio of the surface area forming the tubes with respect to the total surface area (including circular openings and inter-tube voids). Moreover a geometric roughness factor was defined as the ratio of inner, outer, flat top, bottom surface of tube array relative to the corresponding projected area. Thus the $\varphi$ and $H$ factors can be calculated according to:

$$
\begin{array}{r}
\varphi=\frac{8 \pi\left(R_{2}\right)\left(R_{2}-R_{1}\right)}{\sqrt{3}\left(4 R_{2}-2 R_{1}+y\right)^{2}} \\
H=\frac{8 \pi L R_{2}}{\sqrt{3}\left(4 R_{2}-2 R_{1}+y\right)^{2}}
\end{array}
$$

The density of nanotubes per unit area is obtained from the geometric model as:

$$
N_{\mathrm{T}}=\frac{2}{\sqrt{3}\left(4 R_{2}-2 R_{1}+y\right)^{2}}
$$

The values of the geometric parameters for the two types of nanotubes are reported in Table 1. The total developed surface $S_{\mathrm{t}}$ is then given by:

$$
S_{\mathrm{t}}=H \times S_{\text {geo }}
$$

The nanotubular array of $\mathrm{TiO}_{2}-\mathrm{NT}(E G)$ is denser and the developed surface $\left(52 \mathrm{~cm}^{2}\right)$, is about twice that of the $\mathrm{TiO}_{2}-\mathrm{NT}(\mathrm{TB})$ array $\left(27 \mathrm{~cm}^{2}\right)$.

The capacity of space charge layer $C_{\mathrm{sc}}$ in the nanotubular morphology. 
In a semiconducting tubular structure, a space charge region with width $L$ extends circular in the side walls of the tubes as shown in Fig. $2 \mathrm{~b}$. The band bending extends in a half-tube wall and $x$ represents the half-width of the neutral zone. The total depletion regime is obtained for $x=0$.

In ref [2] the resolution of Poisson's equation expressed in cylindrical coordinates leads to a relation between the space charge layer capacitance per surface unit of tube wall, and the geometric parameters $R_{1}$ and $R_{2}$ of the tubes according to equation 6 :

$$
C_{\text {sc }}(\text { tube })=\frac{\varepsilon \varepsilon_{0}}{2 R_{2} \ln \frac{R_{2}-x}{R_{1}}}
$$

where $\varepsilon_{0}$ is the permittivity of free space $\left(\mathrm{F} . \mathrm{cm}^{-1}\right), \varepsilon$ the relative dielectric constant.

A limiting (minimum) value can be estimated for $C_{\mathrm{sc}}$ (tube) taking $x=0$, which corresponds to the total depletion regime across the wall of the tubes. An approximate calculus with the respective geometric parameters and taking $\varepsilon=100$ would lead to limiting values of $3.8 \mu \mathrm{F} \mathrm{cm}^{-2}$ and $8.0 \mu \mathrm{F}$ $\mathrm{cm}^{-2}$ respectively for $\mathrm{TiO}_{2}-\mathrm{NT}(\mathrm{TB})$ and $\mathrm{TiO}_{2}-\mathrm{NT}(\mathrm{EG})$.

\section{Calculation of the width of space charge layer $L$.}

The width of space charge layer in the tube wall is given by [32]

$$
L=\left(\frac{2 \varepsilon_{0} \varepsilon}{e N_{\mathrm{D}}}\right)^{1 / 2}\left(E_{\mathrm{appl}}-E_{\mathrm{fb}}-\frac{k T}{e}\right)^{1 / 2}
$$

where $k$ is the Bolzmann's constant, $N_{\mathrm{D}}$ the carrier density, $E_{\mathrm{fb}}$ the flat band potential, $E_{\text {appl }}$ the applied potential in the gap region and $k T / e=0.025 \mathrm{~V}$ at $298 \mathrm{~K}$ is a negligible value.

Taking $\varepsilon=100, L$ can be estimated as a function of $N_{\mathrm{D}}$, for a given voltage drop. The results for barrier heights of 0.1 and $1 \mathrm{~V}$, and for $N_{\mathrm{D}}$ varying from $10^{18}$ to $10^{21} \mathrm{~cm}^{-3}$ are given in Table 2 and have to be compared to the nanotube wall half-thickness from Table 1 (half-thickness of $10 \mathrm{~nm}$ and $5 \mathrm{~nm}$ are estimated for $\mathrm{TiO}_{2}-\mathrm{NT}(\mathrm{TB})$ and $\mathrm{TiO}_{2}-\mathrm{NT}(E G)$ respectively). It is clear that a high potential drop can only be supported by highly doped tube walls.

Electrochemical impedance measurements

$\mathrm{TiO}_{2}-\mathrm{NT}(\mathrm{TB})$ : impedance diagram in the dark before and after UV illumination. 
A series of impedance measurements was carried out in the dark before and after UV illumination. Before UV illumination, the open circuit potential is about $-0.22 \mathrm{~V} / \mathrm{SCE}$. The impedance diagrams in Bode representation are shown in Fig. 3a for applied potentials between $-0.8 \mathrm{~V}$ and $0.1 \mathrm{~V}$. The decrease of the modulus with decreasing potentials reflects a decrease in the resistance of electron transfer and thus an increase of the electron flow through the space charge region, when the potential gets close to the conduction band. Two time constants are observed for potentials above $-0.3 \mathrm{~V}$, with an increasing contribution of the response at high frequency when the potential increases. In contrast, in the more cathodic potential range, the high frequency contribution is becoming weaker, while the low frequency contribution becomes dominant.

During illumination, the open circuit potential is shifted towards more negative values, -0.73 V/SCE. Since the absorption coefficient of $\mathrm{TiO}_{2}$ in the near-UV is about $10^{4} \mathrm{~cm}^{-1}\left(18000 \mathrm{~cm}^{-1}\right.$ and $3000 \mathrm{~cm}^{-1}$ respectively for wavelengths of $365 \mathrm{~nm}$ and $404 \mathrm{~nm}$ [33]), and taking into account the possible transitions between the valence band and the surface states located below the conduction band, the whole thickness of these layers $(1000 \mathrm{~nm})$ is assumed to be photo-excited. After three hours of UV exposure, and back in the dark during one hour, a set of new impedance diagrams (Fig. 3b) are performed in the dark to evaluate the long-lasting photo-induced changes in the layers. The modulus and phase have now very close values in the potential range under study. Only one time constant at low frequencies is observed and the contribution at high frequency has disappeared.

$\mathrm{TiO}_{2}-N T(E G)$ : impedance diagram in the dark before and after UV illumination.

The open circuit potential which is about $-0.11 \mathrm{~V} / \mathrm{SCE}$ in the dark is shifted towards $-0.67 \mathrm{~V} / \mathrm{SCE}$ when UV light is switched on. Fig. 4 shows the impedance diagrams in Bode representation obtained before and after UV exposure. As in the case of $\mathrm{TiO}_{2}-N T(T B)$, the decrease of the modulus $|Z|$ when the potential decreases, reflects the decreased resistance to electron transport when the potential gets close to the flat band potential. A single time constant appears in the same frequency range below $100 \mathrm{~Hz}$, not only in the situation before UV but also in the situation after UV exposure.

Equivalent Circuit for two types of nanotubular arrays 
In the dark

According to [2] the behaviour of a nanotubular $\mathrm{TiO}_{2}$ thin layer can be well represented with two $R C$ circuits. The first $\left(R_{\mathrm{T}}-C P E\right)$ circuit in the low frequency domain, accounts for the behaviour of the space charge layer of the semiconducting oxide, whereas the second ( $\left.R_{\mathrm{ss}}, C_{\mathrm{ss}}, W_{\mathrm{ss}}\right)$ circuit, in the high frequency range, describes the relaxation of charge via surface states. These two contributions are connected in parallel and the result is in series with the electrolyte resistance $R_{\mathrm{S}}$. The scheme of the corresponding equivalent circuit is reported in Fig. 5a and is used in the present work to describe the behaviour of the two layers in the dark. For the space charge layer a constant phase element is used instead of a pure capacitance. $R_{\mathrm{SS}}$ and $C_{\mathrm{SS}}$ are respectively associated with the resistance and capacitance of the surface states. In the case of $T_{i} O_{2}-N T(T B)$ a Warburg element $\left(W_{\mathrm{SS}}\right)$ is added to obtain a better fit. It has no clearly identified physical meaning, but may reflect a delay for trapping/de-trapping of these surface states. In the case of $\mathrm{TiO}_{2}-\mathrm{NT}(E G)$ a good fit could be obtained without adding the Warburg element and by considering the $R_{\mathrm{T}}$ infinite. This model can fit the real and imaginary parts of impedance with a standard deviation of about $1 \%$, throughout the whole frequency range.

\section{After UV exposure}

In the case of $\mathrm{TiO}_{2}-N T(E G)$ the same equivalent circuit is used before and after UV exposure. On the contrary, in the case of $\mathrm{TiO}_{2}-\mathrm{NT}(\mathrm{TB})$, since a single time constant is observed (Fig. 3b) and the response related to the surface states disappears after UV exposure, the behaviour of the layer can accurately be described using a single $R_{\mathrm{T}}-C P E$ circuit (Fig. 5b). Table 3 gives some numerical results for the electrical components used in these equivalent circuits for two types of layer before and after illumination.

Space charge layer analysis for the two types of nanotubular array before and after UV exposure. Since the behaviour of the space charge zone is close to an ideal capacity (CPE with an exponent between 0.90 and 0.98 in Table 3 ), the estimated capacity $C_{\text {sc }}$ could be calculated using Brugg's equation [34]

$$
C=\left(R Q_{0}\right)^{1 / \mathrm{n}} / R \text { where } R \text { is defined by } 1 / R=1 / R_{\mathrm{S}}+1 / R_{\mathrm{T}}
$$

$Q_{\mathrm{o}}$ is the constant representative of $C P E\left(\mathrm{~F} \mathrm{~cm}^{-2} \mathrm{~s}^{\mathrm{n}-1}\right)$ and $n$ its exponent. 
The variations of the space charge layer capacitance $\left(C_{\mathrm{sc}}\right)$ as a function of the applied potential (between $-0.8 \mathrm{~V}$ and $0.1 \mathrm{~V}$ ), before and after UV exposure, are illustrated in Fig. 6a and 6b, respectively for $\mathrm{TiO}_{2}-\mathrm{NT}(\mathrm{TB})$ and $\mathrm{TiO}_{2}-\mathrm{NT}(\mathrm{EG})$.

For $\mathrm{TiO}_{2}-\mathrm{NT}(\mathrm{TB})$, the limiting value for $\mathrm{Csc}$, when the potential gets very anodic and the space charge layer is completely depleted from its negative charges, is about $2.2 \mu \mathrm{F}$ (before UV), and $248 \mu \mathrm{F}$ (after UV). For $\mathrm{TiO}_{2}-N T(E G)$, the limiting values are $5.2 \mu \mathrm{F}$ and $43.6 \mu \mathrm{F}$ before and after UV respectively.

It is noticeable that for $\mathrm{TiO}_{2}-\mathrm{NT}(\mathrm{TB})$, a significant increase in the capacity $\mathrm{C}_{\mathrm{sc}}$ is observed throughout the potential range when the layer has previously been exposed to UV light. For $\mathrm{TiO}_{2^{-}}$ $N T(E G)$ an increase is still observed, yet much less significant. As a matter of fact, in the depletion region, the capacitance increase is by a factor of 112 for $\mathrm{TiO}_{2}-N T(T B)$, while only by a factor of 8 for $\mathrm{TiO}_{2}-\mathrm{NT}(E G)$.

Case of $\mathrm{TiO}_{2}-\mathrm{NT}(\mathrm{TB})$

Before UV exposure, the value of $2.2 \mu \mathrm{F}$ obtained for the limiting capacitance has to be compared to the limiting value of $3.8 \mu \mathrm{F} / \mathrm{cm}^{2}$ determined from the geometric model for $x=0$ (equation 6). The ration between the two values lead to a rough estimate of $0.58 \mathrm{~cm}^{2}$ for the active surface, which is very close to the geometric surface of the sample $\left(0.64 \mathrm{~cm}^{2}\right)$. It seems therefore that mainly the bottom of the tubes supports the band bending under polarization and that the tube walls are completely depleted from negative charges in this potential range.

After UV exposure, a huge increase of the limiting capacitance $(248 \mu \mathrm{F})$ is observed, leading to a capacity per unit surface of $9.0 \mu \mathrm{F} \mathrm{cm}$, if the whole developed surface of $27 \mathrm{~cm}^{2}$, determined from geometric model calculation, is taken into account. As previously, this limiting value of 9.0 $\mu \mathrm{F} \mathrm{cm}{ }^{-2}$ has to be compared to the limiting value of 3.8 obtained from the geometric model in equation 6 , and we must admit that $x$ is now close to $5 \mathrm{~nm}$. That means that the space charge layer is now limited to a thin thickness at the surface of the tube walls as a consequence of the increase in the charge carrier density during UV exposure.

Case of $\mathrm{TiO}_{2}-\mathrm{NT}(\mathrm{EG})$

Before UV exposure, in the very anodic potential range, the capacitance reaches the limiting value of $5.2 \mu \mathrm{F}$, which has to be compared to the limiting value calculated from the geometric 
model in $\left(8.0 \mu \mathrm{F} \mathrm{cm}^{-2}\right)$. The ratio of 0.65 between the two values indicates that only the flat surface $\left(0.64 \mathrm{~cm}^{2}\right)$ is active in this potential range. Nevertheless if we compare the capacitance variations between $\mathrm{TiO}_{2}-\mathrm{NT}(\mathrm{EG})$ and $\mathrm{TiO}_{2}-\mathrm{NT}(\mathrm{TB})$ in the more cathodic range (Fig. 6), it appears that the former sample shows higher capacitance values, and a higher rate of decrease with the applied potential.

It seems that for $\mathrm{TiO}_{2}-\mathrm{NT}(E G)$, in the dark, the nanotube walls are already active in the cathodic potential range and that they get progressively depleted from negative charges when the potential increases. Moreover, as shown in Fig. 6b, UV exposure of the layer does not significantly modify the capacitance values in the potential range under study. This phenomenon will be discussed in the simulation part.

Surface states analysis for the two types of nanotubular array before and after UV exposure.

The surface states display an exponential dependence of the capacitance values on the applied potential before and after UV, and the plots in log scale are illustrated in Fig. 7. For the $\mathrm{TiO}_{2^{-}}$ $N T(T B)$ sample, an exponential distribution of surface states with a wide capacitance hump appears at about $-0.15 \mathrm{~V}$ which corresponds to additional states in the gap before $\mathrm{UV}$, as discussed already in reference [2]. This quasi-monoenergetic state can be represented by a flat distribution with a narrow $0.22 \mathrm{eV}$ width, and a density of $3 \times 10^{14} \mathrm{~cm}^{-2} \mathrm{eV}^{-1}$ (insert of Fig. 7). Such a combination (exponential distribution and monoenergetic state) is often associated with nanostructured layers [35-37]. After UV exposure, the surface states are modified, leading to the disappearance of the contribution at high frequency in the Bode representation of Fig. 3a.

For the $\mathrm{TiO}_{2}-N T$ (EG) sample, an exponential distribution is observed in the [-0.5 to $\left.0.4 \mathrm{~V}\right]$ potential range for the surface state capacitance, before and after UV exposure, with a slight increase of the capacity value after UV exposure (Fig. 7). Comparing the capacity values for two types of nanotubular arrays before UV exposure, the main difference is the absence of a monoenergetic state in the $\mathrm{TiO}_{2}-\mathrm{NT}(E G)$ sample. The chemical nature of this monoenergetic state will be discussed below. 


\section{Simulation based on the geometric model}

The physical model previously described (Equations 1-6) correlates the space charge layer capacitance $\left(C_{\mathrm{sc}}\right)$ to the geometric parameters of the nanotubes such as inner and outer diameters. Actually the two layers, $\mathrm{TiO}_{2}-\mathrm{NT}(\mathrm{TB})$ and $\mathrm{TiO}_{2}-\mathrm{NT}(E G)$, show very similar geometric parameters, but the capacitance variations with applied potentials are different. This shows that geometric parameters are not the only parameters that have to be taken into account and that the drop voltage at the interface $\mathrm{TiO}_{2} /$ electrolyte is likely to be differently shared between the space charge layer and the Helmholtz layer in the two cases.

A simulation was performed which considers a capacitive voltage divider between the capacities $\left(C_{\mathrm{sc}}+C_{\mathrm{ss}}\right)$ at the semiconductor side on one hand and the Helmholtz capacitance $C_{\mathrm{H}}$ at the electrolyte side on the other hand. To each variation $\mathrm{d} E$ of the applied potential, corresponds a variation of the potential drop $\mathrm{d} E_{\mathrm{sc}}$ in the walls of the nanotubes and a variation $\mathrm{d} x$ of the width of the space charge layer according to:

$$
\begin{aligned}
& \mathrm{d} E_{\mathrm{sc}}=\mathrm{d} E \frac{C_{\mathrm{H}}}{C_{\mathrm{H}}+C_{\mathrm{sc}}+C_{\mathrm{ss}}} \\
& \mathrm{d} x=\mathrm{d} E_{\mathrm{sc}} \frac{\varepsilon \varepsilon_{0}}{e N\left(R_{2}-x\right) \cdot \ln \left(\frac{R_{1}}{R_{2}-x}\right)}
\end{aligned}
$$

These two relationships allow a simulation of the curve $C_{\mathrm{sc}}(E)$ point by point by successive iterations, starting from the most cathodic potential $-0.8 \mathrm{~V}$, at which the whole surface of the tube walls $\left(S_{\mathrm{t}}\right)$ and the flat surface at the bottom of the tubes $\left(S_{\mathrm{fl}}\right)$ are assumed to be active. At $-0.8 \mathrm{~V}$ the initial $C_{\mathrm{sc}}$ value is the experimental value and $x$ is calculated from equation 5 .

In equation (9), $C_{\mathrm{H}}$ was taken constant and equal to $10 \mu \mathrm{F} \mathrm{cm}$, which is a usual value for Helmholz layer capacitance. The variation of $C_{\mathrm{ss}}$ as a function of potential is taken from the experimental relations of Fig. 7.

From the geometric model, the surface of the tube walls is given by equation (11):

$S_{\mathrm{t}}=4 \pi R_{2} h N_{\mathrm{t}} S_{\text {geo }}$

where $N_{\mathrm{t}}$ is the tube density and $S_{\text {geo }}$ the geometric surface $\left(0.64 \mathrm{~cm}^{2}\right)$. 
If we consider that the tube walls get progressively depleted from the negative charges, when the potential gets more anodic, the active surface itself vary as a function of the potential. At first approximate an exponential decrease of the active surface of the walls with applied potential $E_{\mathrm{i}}$ was taken into account according to:

$S_{\mathrm{t}}=4 \pi R_{2} h N_{\mathrm{t}} S_{\text {geo }} \times \exp \left(\frac{-\left(E_{\mathrm{i}}-E_{\mathrm{fb}}\right)}{\Delta E}\right)$

$E_{\mathrm{fb}}$ is the flat band potential fixed at a value between -0.72 and $-0.80 \mathrm{~V}$ for the simulated curves, and $\Delta E$ is an adjustable parameter.

$S_{\mathrm{fl}}$ represents the openings and voids, at the bottom of the tubes and is given by equation (13):

$S_{\mathrm{fl}}=S_{\text {geo }} \cdot\left(1-\frac{8 \pi R_{2}\left(R_{2}-R_{1}\right)}{\sqrt{3} \cdot\left(4 R_{2}-2 R_{1}+y\right)^{2}}\right)$

The total space charge layer capacity $C_{\mathrm{i}}$ (tube walls + flat part) at a given applied potential $E_{\mathrm{i}}$ is given by:

$$
C_{\mathrm{i}}\left(E_{\mathrm{i}}\right)=C_{\mathrm{sc}_{\mathrm{i}}} \cdot S_{\mathrm{t}}+C_{\mathrm{fl}_{\mathrm{i}}} \cdot S_{\mathrm{fl}}
$$

The contribution of the flat part at the bottom of the tubes to the total capacitance was estimated using the classical Mott Schottky relation:

$C_{\mathrm{fl}}=\sqrt{\frac{\varepsilon \varepsilon_{0} N_{\mathrm{D}}}{2}} \cdot \frac{1}{\sqrt{E-E_{\mathrm{fb}}}}$

The results of the simulations performed using MathCad ${ }^{\mathrm{TM}}$ software and leading to the best fit with the experimental results are reported in Fig. 8 and the values of the fitting parameters in Tables 4 and 5 .

For $\mathrm{TiO}_{2}-N T(T B)$, in the dark, the height of the active tube wall is negligible $(10 \mathrm{~nm})$ in comparison with the whole tube length $(1000 \mathrm{~nm})$ (Table 3). This result confirms the previous assumption, that in this kind of layer, only the flat surface at the bottom of the tubes supports band bending under polarization. The carrier density (about $10^{18} \mathrm{~cm}^{-3}$ ) is also in agreement with previous estimations [2]. After UV exposure, the simulations reflect the activation of the tube walls and a noticeable increase in the charge carrier density $\left(>10^{20} \mathrm{~cm}^{-3}\right)$. Such a high doping level of the walls is in accordance with a space charge region of small thickness, as previously calculated (about $3 \mathrm{~nm}$ and $11 \mathrm{~nm}$ for a barrier height of respectively $0.1 \mathrm{~V}$ and $1 \mathrm{~V}$ in Table 2). 
For $\mathrm{TiO}_{2}-N T(E G)$, the situation is more complex: the working surface is supposed to change progressively due to progressive depletion of electrons in the wall of the nanotubes, when the applied potential gets more anodic. The carrier density in the tube walls is already high before UV exposure $\left(210^{20} \mathrm{~cm}^{-3}\right)$ and does not significantly increase after UV exposure $\left(3.510^{20} \mathrm{~cm}^{-3}\right)$. For both types of layers, the assumption of a flat band potential between -0.7 and $-0.8 \mathrm{~V}$, leads to a good agreement between the simulated and the experimental curves.

\section{Discussion}

$\mathrm{TiO}_{2}(\mathrm{NT})$ layers synthesized using the same anodization parameters, but in two different media, show different impedance responses, which highlight the influence of the morphology and the geometric parameters of a nanotubular layer. Whereas the thickness of the tube walls and the charge carrier density seems determinant for the semiconducting properties, the roughness of the surface and maybe the inter-tubular connecting points play a significant role on the behaviour of surface states.

\section{Thickness of the tube walls and charge carrier concentration}

Since the tube walls are assumed to support the band bending variation under polarization, the ratio between the wall half-thickness $w / 2$ and the width of the space charge layer $(L)$ is a critical parameter.

- If $w / 2>L$, the band bending may extend to a few tens of nm throughout the halfthickness of the wall in a wide potential range (Fig. 9a), depending on the doping level.

- If $w / 2<L$, flat-band condition exists in the tube wall (Fig. 9b) and band bending can only occur at the bottom of the tubes.

The tubes prepared in ethylene glycol containing $\mathrm{NH}_{4} \mathrm{~F}$ have wall half-thickness of about $5 \mathrm{~nm}$ and a carrier density of about $10^{20} \mathrm{~cm}^{-3}$. According to Table 2, the space charge layer is lower than $5 \mathrm{~nm}$ for a voltage drop of $0.1 \mathrm{~V}$ but gets higher than $5 \mathrm{~nm}$, when the voltage drop increases until $1 \mathrm{~V}$. That indicates that the walls are progressively depleted under anodic polarization, 
passing from a situation where the tubes are totally active in the cathodic range towards a situation where the contribution of the tube walls can be neglected.

The tubes synthesized in the tetrabutylammonium fluoride / formamide solution have thicker walls $(\mathrm{w}=20 \mathrm{~nm})$ than the former sample, but lower carrier concentration (about $10^{18} \mathrm{~cm}^{-3}$ ). According to Table 2, the space charge layer is then much wider (32 $\mathrm{nm}$ for a barrier height of 0.1 V) than the half-thickness of the wall $(10 \mathrm{~nm})$ and band bending is not possible in the tube walls, but only at the flat surface at the bottom, in the potential range under study.

\section{Surface states}

In the $\mathrm{TiO}_{2}-\mathrm{NT}(\mathrm{TB})$ sample, a monoenergetic state was observed before illumination, located close to $0.5 \mathrm{eV}$ below the edge of conduction band. It has been suggested that this state is correlated with water adsorbed at the surface of $\mathrm{TiO}_{2}$. Some authors $[25,28]$ have shown that water adsorbed on the surface in molecular form is able to trap negative charges. According to $\mathrm{J}$ Yang et al [38], an undissociated $\mathrm{H}_{2} \mathrm{O}$ molecule adsorbed on the surface of nanoparticles generates a localized energy state at $0.79 \mathrm{eV}$ below the edge of the conduction band. Furthermore Selloni et al [29] have clearly demonstrated by DFT type calculations, that water adsorption is in molecular form only at some crystalline sites, such as steps or "terraces" of the (101) plane of anatase. The corresponding adsorption energy is relatively low $(<1 \mathrm{eV})$, enabling external energy to cause dissociation of the water molecule. Accordingly IR analyses [39] have evidenced that UV exposure is able to dissociate the adsorbed water molecules and to convert them into hydroxyl groups. The absence of such states in the layer synthesized in ethylene glycol is likely to be related to the difference of roughness between the two types of samples, with much smoother and well separated tube walls in the $\mathrm{TiO}_{2}-\mathrm{NT}(E G)$ sample.

UV exposure of $\mathrm{TiO}_{2}-\mathrm{NT}(\mathrm{TB})$ induced several long-lasting changes. One of them was the disappearance of the monoenergetic state as a result of the dissociation of adsorbed water molecules. The following mechanism was proposed by McQuillian [39] to explain the processes leading to the hydroxylation of $\mathrm{TiO}_{2}$ surfaces

$\mathrm{Ti}-\mathrm{OH}_{2}+\mathrm{h}^{+}{ }_{(\mathrm{VB})} \rightarrow \mathrm{Ti}-\mathrm{OH} \bullet+\mathrm{H}^{+}{ }_{(\mathrm{aq})}$

$\mathrm{Ti}-\mathrm{O}\left(\mathrm{H}^{+}\right)-\mathrm{Ti}+\mathrm{e}_{(\mathrm{CB})}^{-} \rightarrow \mathrm{Ti}-\mathrm{O}(\mathrm{H})-\mathrm{Ti}$

Overall reaction: 
$\mathrm{H}_{2} \mathrm{O}+\mathrm{h}^{+}{ }_{(\mathrm{VB})}+\mathrm{e}_{(\mathrm{CB})}^{-} \rightarrow \mathrm{OH} \bullet+\mathrm{H}_{(\text {aq) }}^{+}+\mathrm{e}_{\text {(trapped) }}^{-}$

However these equations do not reflect the increase in doping level accompanying the dissociation of water molecule. We propose that the dissociation of adsorbed water causes an insertion of hydrogen into the network of $\mathrm{TiO}_{2}$, similar to the phenomenon observed by Chen [40] under cathodic polarization. In our case, atomic hydrogen photo-generated during the dissociation of water would be inserted into the network according to

$\mathrm{H}_{\mathrm{ad}} \rightarrow \mathrm{H}^{+}+\mathrm{e}^{-}$

The electrons produced by this reaction would be responsible for increasing the number of carriers in $\mathrm{TiO}_{2}$ and the decrease of the space charge layer width and the possibility of band bending in the tube walls after illumination.

\section{Conclusion}

In this work, two types of $\mathrm{TiO}_{2}$ nanotubes have been synthesized with different morphologies by anodisation of titanium foils in fluoride-containing solutions. Nanotubes with rough (smooth) walls were obtained in formamide (ethylene glycol) electrolytes respectively. The influence of nanotube morphology on their electrical behaviour was investigated by electrochemical impedance spectroscopy in the dark within the frame of an electrical model taking into account the nanotubular geometry. The electrical properties were evaluated before and after UV exposure to check the presence of long lasting effects due to UV illumination. The wall thickness was found to be a key parameter for controlling the potential drop accross the tube walls and then the surface electron concentration. Thus smooth nanotubes with very thin wall thickness were found fully depleted in a large potential domain yielding nanotubes electrically inactive in the dark. Another important difference was observed about the surface state distribution in the $\mathrm{TiO}_{2}$ band gap: an exponential distribution with energy close to the bottom of the conduction band is observed in both cases, but for the rough nanotubes a monoenergetic state is found in addition to the exponential base line. This state disappears after UV exposure. It has been assigned to water molecules adsorbed at crystallographic defects, which are dissociated into hydroxyl species under UV illumination. 


\section{References}

[1] Gong D, Grimes CA, Varghese OK, Hu WC, Singh RS, Chen Z, Dickey EC (2001) J Mater Res 16:3331-3334

[2] Pu P, Cachet H, Sutter EMM (2010) Electrochim Acta 55:5938-5946

[3] Nishikiori H, Qian W, El-Sayed MA, Tanaka N, Fujii T (2007) J Phys Chem C 111:9008-9011

[4] Kondo JN, Domen K (2008) Chem Mat 20:835-847

[5] Varghese OK, Gong D, Paulose M, Ong KG, Dickey EC, Grimes CA (2003) Adv Mater 15:624-627

[6] Mor GK, Varghese OK, Paulose M, Ong KG, Grimes CA (2006) Thin Solid Films 496:42-48

[7] Varghese OK, Grimes CA (2003) J Nanosci Nanotechnol 3:277-293

[8] Balaur E, Macak JM, Tsuchiya H, Schmuki P (2005) J Mater Chem 15:4488-4491

[9] Shankar K, Mor GK, Paulose M, Varghese OK, Grimes CA (2008) J Non-Cryst Solids $354: 2767-2771$

[10] Sun WT, Yu Y, Pan HY, Gao XF, Chen Q, Peng LM (2008) J Am Chem Soc 130:1124-1125

[11] Albu SP, Ghicov A, Macak JM, Hahn R, Schmuki P (2007) Nano Lett 7:1286-1289

[12] Zhang ZH, Yuan Y, Shi GY, Fang YJ, Liang LH, Ding HC, Jin LT (2007) Environ Sci Technol 41:6259-6263

[13] Atyaoui A, Bousselmi L, Cachet H, Pu P, Sutter EMM (2011) J Photochem Photobiol A 224:71-79

[14] Chen SG, Paulose M, Ruan C, Mor GK, Varghese OK, Grimes CA (2006) J Photochem Photobiol A 177:177-184

[15] Seabold JA, Shankar K, Wilke RHT, Paulose M, Varghese OK, Grimes CA, Choi KS (2008) Chem Mater 20:5266-5273

[16] Mazare A, Paramasivam I, Lee K, Schmuki P (2011) Electrochem Commun13:1030-1034

[17] Hoyer P (1996) Langmuir 12:1411-1413

[18] Shinggubara S (2003) J Nano Res 5:17-30

[19] Kasuga T, Hiramatsu M, Hoson A, Sekino T, Niihara K (1998) Langmuir 14: 3160-3163

[20] Adachi M, Murata Y, Okada I, Yoshikawa Y (2003) J Electrochem Soc 150: G488-G493

[21] Macak JM, Tsuchiya H, Ghicov A, Yasuda K, Hahn R, Bauer S, Schmuki P (2007) Curr Opin Solid State Mater Sci 11:3-18 
[22] Ruan C, Paulose M, Varghese OK, Grimes CA (2006) Sol Energy Mater Sol Cells 90:12831295

[23] Tsuchiya H, Macak JM, Taveira L, Balaur E, Ghicov A, Sirotna K, Schmuki P (2005) Electrochem Commun 7: 576-580

[24] Taveira L, Sagüés A, Macak JM, Schmuki P (2008) J Electrochem Soc 155: C293-C302

[25] Fabregat-Santiago F , Barea EM, Bisquert J. Mor GK, Shankar K, Grimes CA (2008) J Am Chem Soc 130:11312- 11316

[26] Prakasam HE, Shankar K, Paulose M, Varghese OK, Grimes CA (2007) J Phys Chem C 111:7235-7241

[27] Paulose M, Shankar K, Yoriya S, Prakasam HE, Varghese OK, Mor GK, Latempa TJ, Fitzgerald A, Grimes CA (2006) J Phys Chem B 110: 16179-16184

[28] Gong X, Selloni A, Batzill M, Diebold U (2006) Nat Mater 5:665-670

[29] Gong X, Selloni A (2007) J Catal 249:134-139

[30] Paulose M, Shankar K, Varghese OK, Mor GK, Hardin B, Grimes CA (2006) Nanotechnology 17:1446-1448

[31] Paulose M, Varghese OK, Mor GK, Grimes CA, Ong KG (2006) Nanotechnology 17:398402

[32] Van de Krol R, Goossens A, Schoonman J (1997) J Electrochem Soc 144:1723-1727

[33] Hafidi K, Azizan M, Ijdiyaou Y, Ameziane EL (2004) Act Passive Electron Compon 27:169181

[34] Brugg GJ, Van Den Eeden ALG, Sluyters-Rehbach M, Sluyters GH (1984) J Electroanal Chem 176: 275-295

[35] Bisquert J (2008) Phys Chem Chem Phys 10:49-72

[36] Bisquert J, Fabregat-Santiago F, Mora-Seró I, Garcia-Belmonte G, Barea EM, Palomares M (2008) Inorg Chim Acta 361:684-698

[37] Haque SA, Tachibana Y, Willis RL, Moser JE, Grätzel M, Klug DR, Durrant JR (2008) J Phys Chem B 104:538-547

[38] Yang J, Warren DS, Keith Gordon C, McQuillan AJ (2007) J Appl Phys 101:023714

[39] Savory DM, Warren DS, McQuillan AJ (2011) J Phys Chem C 115:902- 907

[40] Chen WP, Wang Y, Chan HLW (2008) Appl Phys Lett 92:112907 


\section{Figure captions}

Fig. 1: SEM images of nanotubular array: a) $\mathrm{TiO}_{2}-N T(T B)$ obtained by oxidation of titanium in formamide containing tetrabutylammonium fluoride b) $\mathrm{TiO}_{2}-N T(E G)$ obtained by oxidation of titanium in ethylene glycol containing $\mathrm{NH}_{4} \mathrm{~F}$

Fig. 2: Geometric model for $\mathrm{TiO}_{2}$ nanotubular array (a) top view (b) cross section view of nanotube array and potential drop inside the tube wall

Fig. 3: Impedance diagrams in Bode representation of $\mathrm{TiO}_{2}-N T(\mathrm{~TB})$ in $\mathrm{Na}_{2} \mathrm{SO}_{4}(1 \mathrm{M})$, in the dark at different applied potentials a) before UV exposure b) after UV exposure

Fig. 4: Impedance diagrams in Bode representation of $T i O_{2}-N T(E G)$ in $\mathrm{Na}_{2} \mathrm{SO}_{4}(1 \mathrm{M})$ in the dark at different applied potentials a) before UV exposure b) after UV exposure

Fig. 5: Equivalent circuits used to characterize the electrochemical behaviour in the dark a) before and after UV exposure for $\mathrm{TiO}_{2}-N T(E G)$ and before UV exposure for $\mathrm{TiO}_{2}-\mathrm{NT}(\mathrm{TB})$ b) after UV exposure for $\mathrm{TiO}_{2}-\mathrm{NT}(\mathrm{TB})$

Fig. 6: Variations of the space charge layer capacitance $\left(C_{\mathrm{sc}}\right)$ as a function of the applied potential in the dark before and after UV exposure

a) for $\mathrm{TiO}_{2}-\mathrm{NT}(\mathrm{TB})$ b) for $\mathrm{TiO}_{2}-\mathrm{NT}(\mathrm{EG})$

Fig. 7: Variations of the surface state capacitance $\left(C_{\mathrm{ss}}\right)$ as a function of the applied potential for $\mathrm{TiO}_{2}-\mathrm{NT}(\mathrm{TB})$ in the dark before UV exposure and for $\mathrm{TiO}_{2}-N T(E G)$ in the dark before and after UV exposure. Insert: magnification of the additional capacitance due to surface states distributed around $-0.1 \mathrm{~V}$ (width $0.22 \mathrm{eV}$, density: $3.10^{14} \mathrm{~cm}^{-2} \mathrm{eV}^{-1}$ )

Fig. 8: Comparison between experimental and simulated values of space charge capacitance as function of applied potential a) for $\mathrm{TiO}_{2}-N T(T B)$ before UV

b) for $\mathrm{TiO}_{2}-\mathrm{NT}(\mathrm{TB})$ after UV

c) for $\mathrm{TiO}_{2}-N T(E G)$ before UV

d) for $\mathrm{TiO}_{2}-\mathrm{NT}(E G)$ after UV

Fig. 9: Comparison between wall thickness $(w)$ and width of space charge layer $(L)$
a) $w / 2>L$
b) $w / 2<L$ 
Table 1 Geometric parameters of two types of $\mathrm{TiO}_{2}$ nanotubular array

\begin{tabular}{|c|c|c|c|c|c|c|c|c|c|}
\hline & \multicolumn{4}{|c|}{ Values estimated by SEM-FEG } & \multicolumn{5}{|c|}{ Calculated values } \\
\hline Samples & $\begin{array}{r}R_{1} \\
\mathrm{~nm}\end{array}$ & $\begin{array}{c}R_{2} \\
\mathrm{~nm}\end{array}$ & $\begin{array}{c}w \\
\mathrm{~nm}\end{array}$ & $\begin{array}{c}h \\
\mathrm{~nm}\end{array}$ & $\begin{array}{c}y \\
\mathrm{~nm}\end{array}$ & $\begin{array}{c}N_{\mathrm{t}} \\
\mathrm{cm}^{-2}\end{array}$ & $\varphi$ & $\boldsymbol{H}$ & $\begin{array}{c}S_{\mathrm{t}} \\
\mathbf{c m}^{2}\end{array}$ \\
\hline $\mathrm{TiO}_{2}-\mathrm{NT}(\mathrm{TB})$ & 25 & 35 & 20 & 1000 & 20 & $10^{10}$ & 0.42 & 42 & 27 \\
\hline $\mathrm{TiO}_{2}-\mathrm{NT}(\mathrm{EG})$ & 21 & 26 & 10 & 1200 & 13 & $2 \times 10^{10}$ & 0.36 & 80 & 52 \\
\hline
\end{tabular}

Table 2 Width of the space charge layer (L) calculated for different voltage drop values.

\begin{tabular}{|c|c|c|}
\hline $\begin{array}{c}\boldsymbol{N}_{\mathbf{D}} \\
\mathbf{c m}^{\mathbf{- 3}}\end{array}$ & $\begin{array}{c}\boldsymbol{L} \text { for } \mathbf{0 . 1} \mathbf{~ V} \\
\mathbf{n m}\end{array}$ & $\begin{array}{c}\boldsymbol{L} \text { for } \mathbf{~ V} \\
\mathbf{n m}\end{array}$ \\
\hline $10^{18}$ & 32 & 106 \\
\hline $10^{19}$ & 10 & 33 \\
\hline $10^{20}$ & 3.2 & 11 \\
\hline $10^{21}$ & 1.0 & 3.3 \\
\hline
\end{tabular}


Table 3 Some fitted values for the electrical components determined with the equivalent circuits of Fig. 5.

\begin{tabular}{|c|c|c|c|c|c|c|c|c|}
\hline \multicolumn{2}{|c|}{ Samples } & $\begin{array}{c}E \\
\mathrm{~V} / \mathrm{SCE}\end{array}$ & $\begin{array}{c}\boldsymbol{R}_{\mathbf{T}} \\
\boldsymbol{\Omega}\end{array}$ & $\begin{array}{c}Q_{0} \\
\mu \Omega^{-1} s^{n}\end{array}$ & $\begin{array}{l}C_{\mathrm{sc}} \\
\mu \mathrm{F}\end{array}$ & $n$ & $\begin{array}{c}\boldsymbol{R}_{\mathrm{ss}} \\
\boldsymbol{\Omega}\end{array}$ & $\begin{array}{l}C_{\mathrm{ss}} \\
\mu \mathrm{F}\end{array}$ \\
\hline \multirow{6}{*}{$\mathrm{TiO}_{2}-\mathrm{NT}(\mathrm{EG})$} & \multirow{3}{*}{$\begin{array}{c}\text { Before } \\
\text { UV }\end{array}$} & -0.7 & $9 \times 10^{4}$ & 227 & 199 & 0.98 & - & - \\
\hline & & -0.5 & $8 \times 10^{4}$ & 41 & 4.2 & 0.91 & 2.0 & 159 \\
\hline & & -0.2 & $1.4 \times 10^{5}$ & 10 & 2.4 & 0.90 & 181 & 54 \\
\hline & \multirow{3}{*}{$\begin{array}{c}\text { After } \\
\text { UV }\end{array}$} & -0.7 & $4.4 \times 10^{4}$ & 476 & 422 & 0.98 & - & - \\
\hline & & -0.5 & $3.6 \times 10^{4}$ & 410 & 340 & 0.98 & - & - \\
\hline & & -0.2 & $1.0 \times 10^{5}$ & 337 & 297 & 0.98 & - & - \\
\hline \multirow{6}{*}{$\mathrm{TiO}_{2}-\mathrm{NT}(\mathrm{EG})$} & \multirow{3}{*}{$\begin{array}{c}\text { Before } \\
\text { UV }\end{array}$} & -0.7 & - & 831 & 3204 & 0.98 & 3.6 & 213 \\
\hline & & -0.5 & - & 393 & 1545 & 0.98 & 5.6 & 96 \\
\hline & & -0.2 & - & 164 & 652 & 0.99 & 6.3 & 42 \\
\hline & \multirow{3}{*}{$\begin{array}{c}\text { After } \\
\text { UV }\end{array}$} & -0.7 & - & 1596 & 2670 & 0.90 & 0.9 & 419 \\
\hline & & -0.5 & - & 589 & 814 & 0.96 & 6.8 & 98 \\
\hline & & -0.2 & - & 263 & 821 & 0.98 & 6.3 & 55 \\
\hline
\end{tabular}


Table 4 Calculated parameters for $\mathrm{TiO}_{2}-\mathrm{NT}(\mathrm{TB})$.

\begin{tabular}{l|ccccccccc}
\hline & Parameters & $\begin{array}{c}\boldsymbol{R}_{\mathbf{1}} \\
\mathbf{n m}\end{array}$ & $\begin{array}{c}\boldsymbol{R}_{\mathbf{2}} \\
\mathbf{n m}\end{array}$ & $\begin{array}{c}\boldsymbol{h} \\
\mathbf{n m}\end{array}$ & $\begin{array}{c}\boldsymbol{y} \\
\mathbf{n m}\end{array}$ & $\begin{array}{c}\boldsymbol{N}_{\mathbf{D} \text { (tubes) }} \\
\mathbf{c m}^{-3}\end{array}$ & $\begin{array}{c}\boldsymbol{N}_{\mathbf{D} \text { (flat) }} \\
\mathbf{c m}^{-3}\end{array}$ & $\begin{array}{c}\boldsymbol{V}_{\mathbf{f b}} \\
\mathbf{V} / \mathbf{S C E}\end{array}$ & $\begin{array}{c}\boldsymbol{C}_{\mathbf{H}} \\
\mu \mathbf{F} / \mathbf{c m}^{2}\end{array}$ \\
\cline { 2 - 9 } & $\begin{array}{c}\text { Geometric } \\
\text { Values }\end{array}$ & 25 & 35 & 1000 & 20 & & & & \\
\hline \multirow{2}{*}{ Before UV } & Fitting values & 25 & 35 & 10.5 & 20 & $1.3 \times 10^{18}$ & $9.5 \times 10^{18}$ & -0.72 & 10 \\
\hline \multirow{2}{*}{ After UV } & Fitting values & 25 & 35 & 1000 & 20 & $4 \times 10^{20}$ & $1 \times 10^{20}$ & -0.80 & 10 \\
\hline
\end{tabular}

Table 5 Calculated parameters for $\mathrm{TiO}_{2}-\mathrm{NT}(E G)$.

\begin{tabular}{l|ccccccccc}
\hline & Parameters & $\begin{array}{c}\boldsymbol{R}_{\mathbf{1}} \\
\mathbf{n m}\end{array}$ & $\begin{array}{c}\boldsymbol{R}_{\mathbf{2}} \\
\mathbf{n m}\end{array}$ & $\begin{array}{c}\mathbf{h} \\
\mathbf{n m}\end{array}$ & $\begin{array}{c}\boldsymbol{y} \\
\mathbf{n m}\end{array}$ & $\begin{array}{c}\boldsymbol{N}_{\mathbf{D} \text { (tubes) }} \\
\mathbf{c m}^{-3}\end{array}$ & $\begin{array}{c}\boldsymbol{N}_{\mathbf{D} \text { (flat) }} \\
\mathbf{c m}^{-3}\end{array}$ & $\begin{array}{c}\boldsymbol{V}_{\mathbf{f b}} \\
\mathbf{V} / \mathbf{S C E}\end{array}$ & $\begin{array}{c}\boldsymbol{C}_{\mathbf{H}} \\
\mu \mathbf{F} / \mathbf{c m}^{2}\end{array}$ \\
\cline { 2 - 9 } & $\begin{array}{c}\text { Geometric } \\
\text { Values }\end{array}$ & 21 & 26 & 1200 & 13 & & & & \\
\hline \multirow{2}{*}{ Before UV } & Fitting values & 21 & 28 & 1200 & 15 & $1.9 \times 10^{20}$ & $7 \times 10^{18}$ & $-0,80$ & 10 \\
\hline \multirow{2}{*}{ After UV } & Fitting values & 21 & 28 & 1200 & 15 & $3.5 \times 10^{20}$ & $1 \times 10^{19}$ & $-0,80$ & 10 \\
\hline
\end{tabular}


Fig 1

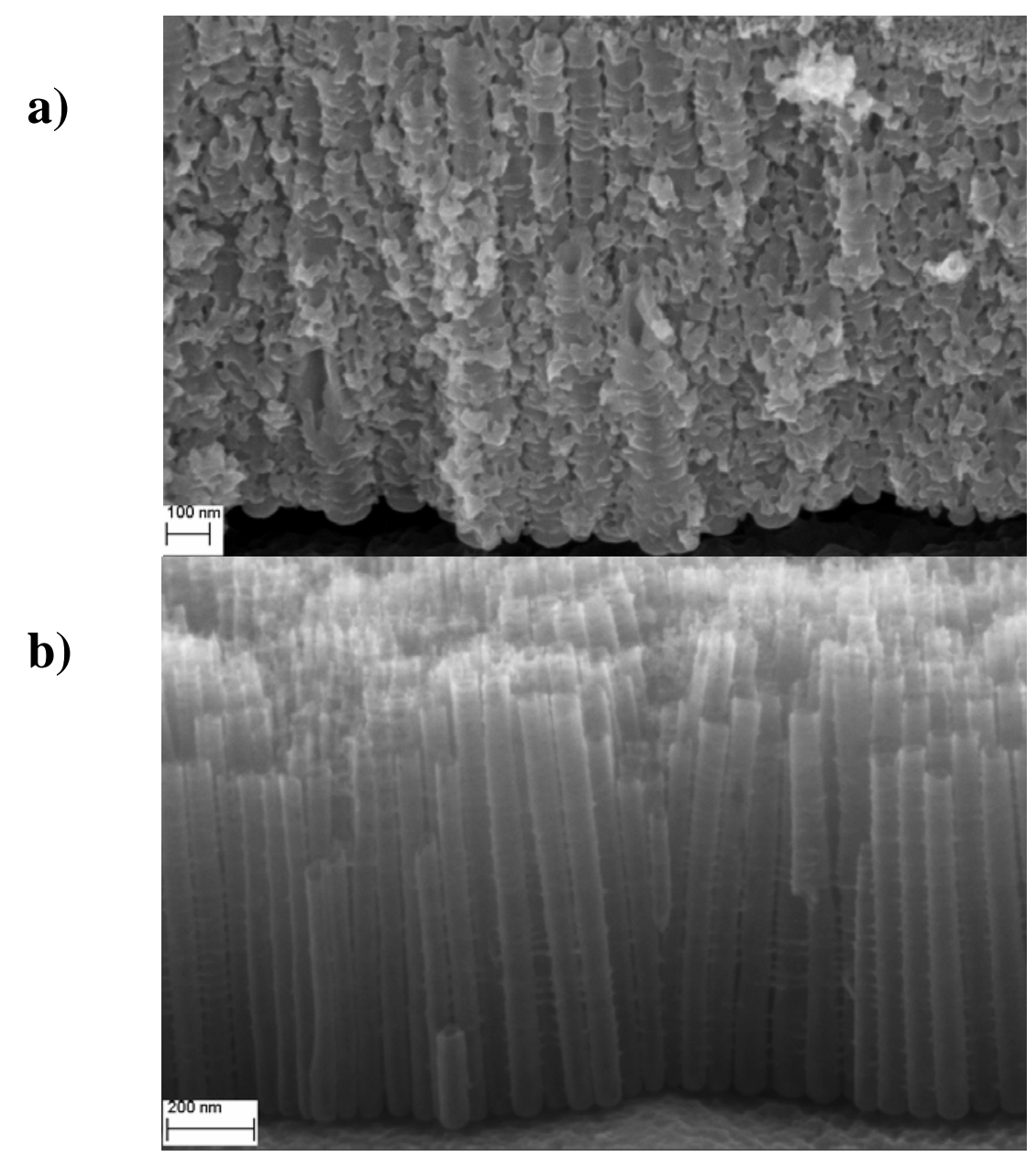


Fig 2

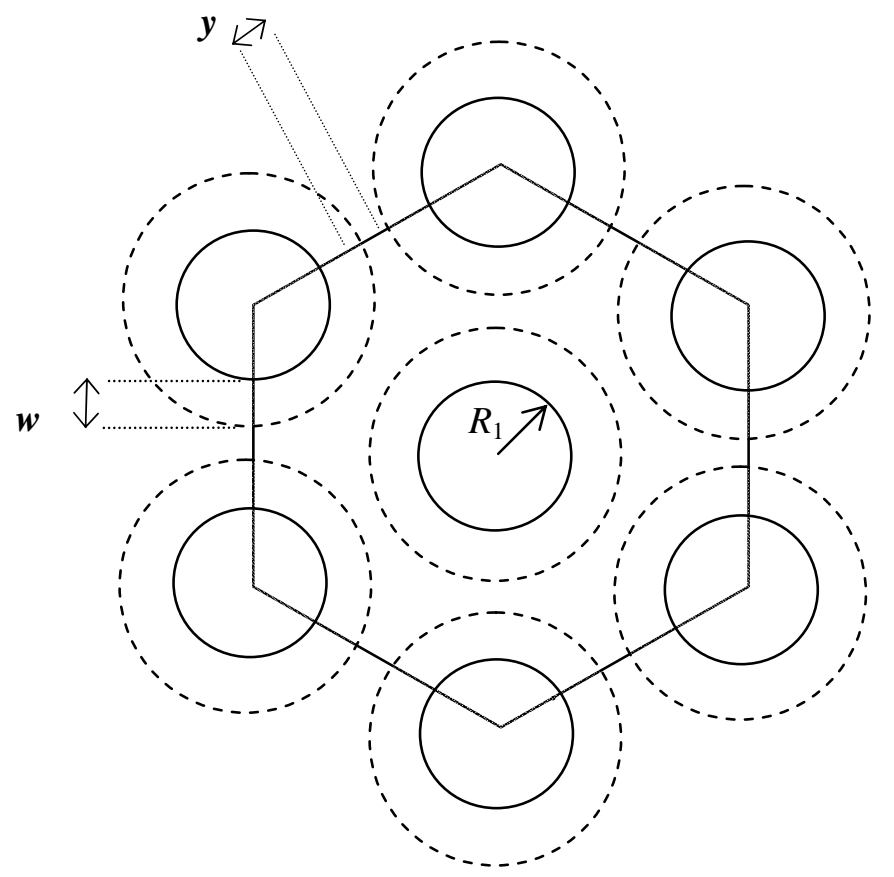

a)

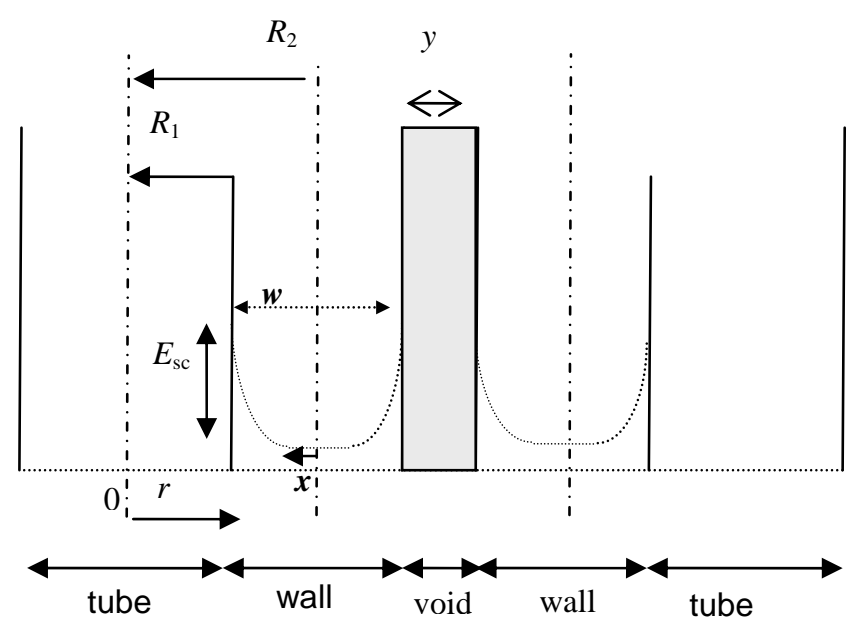

b) 
Fig 3

a)
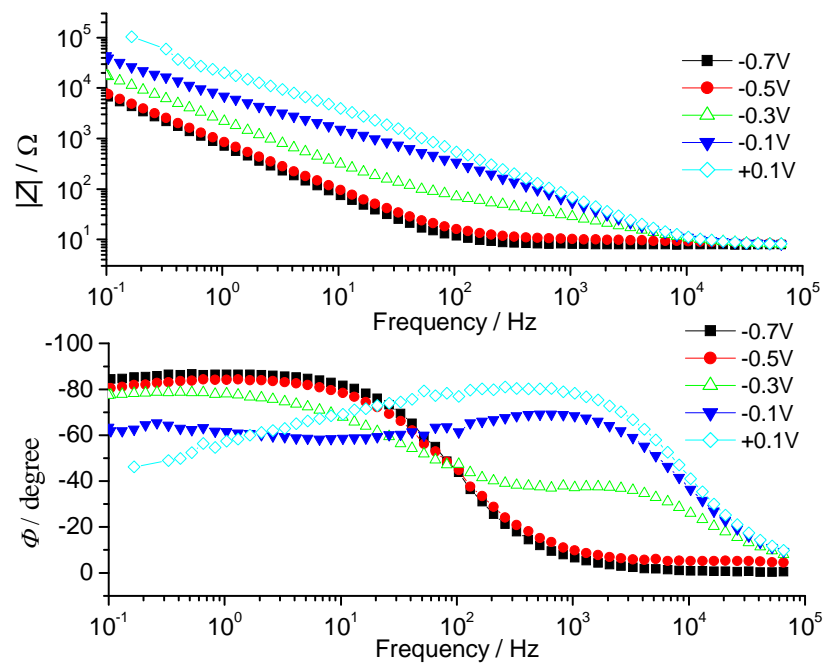

b)

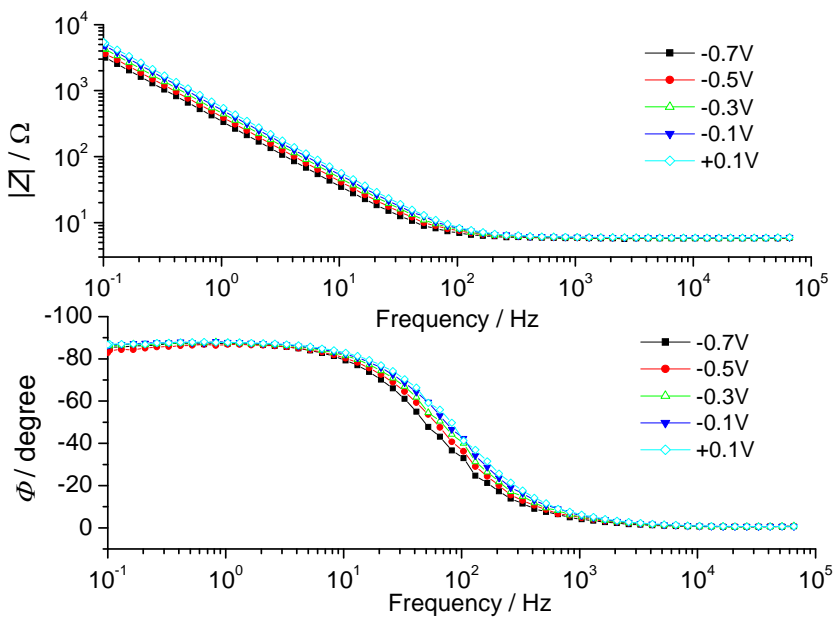


Fig 4
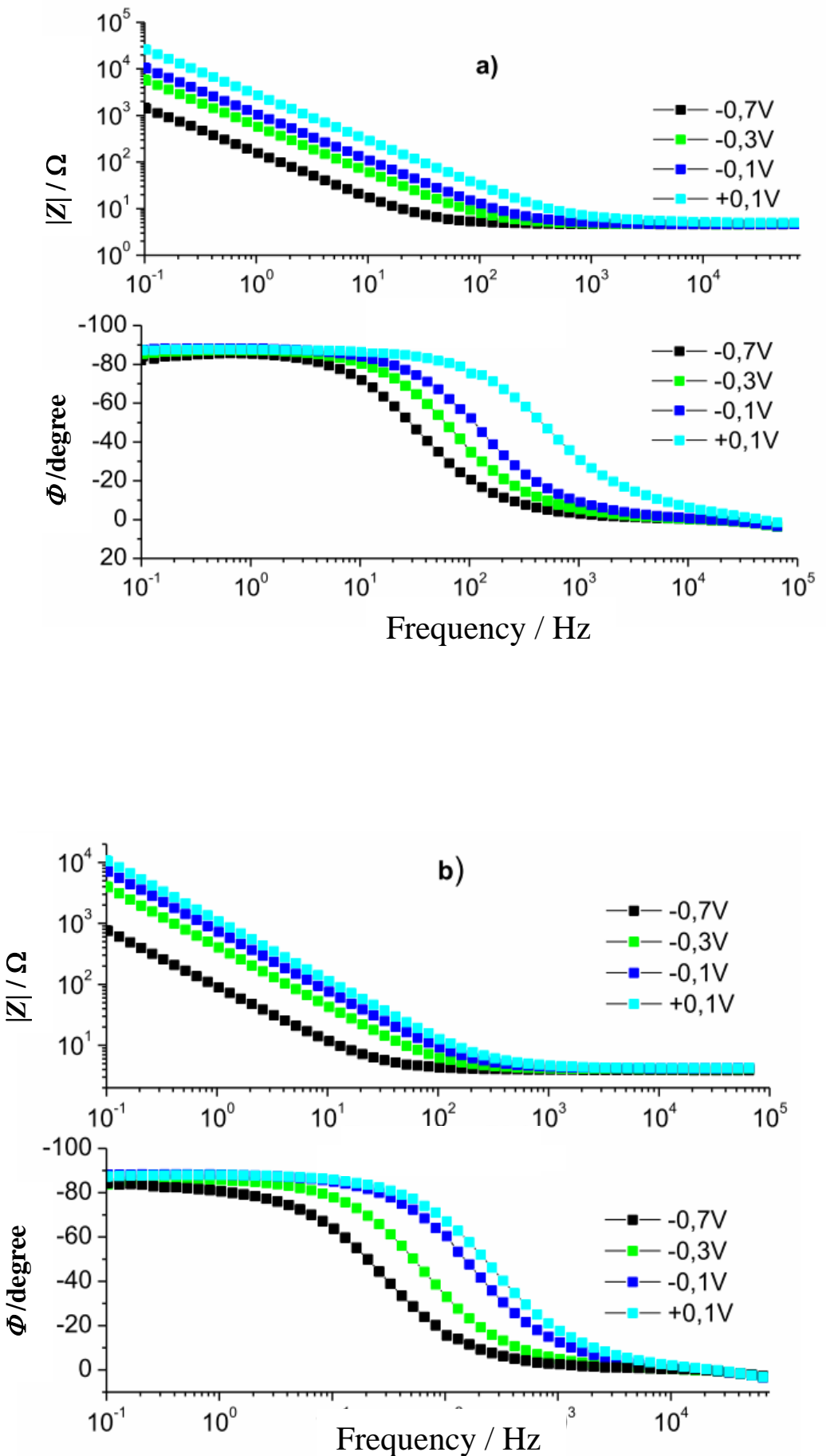
Fig 5

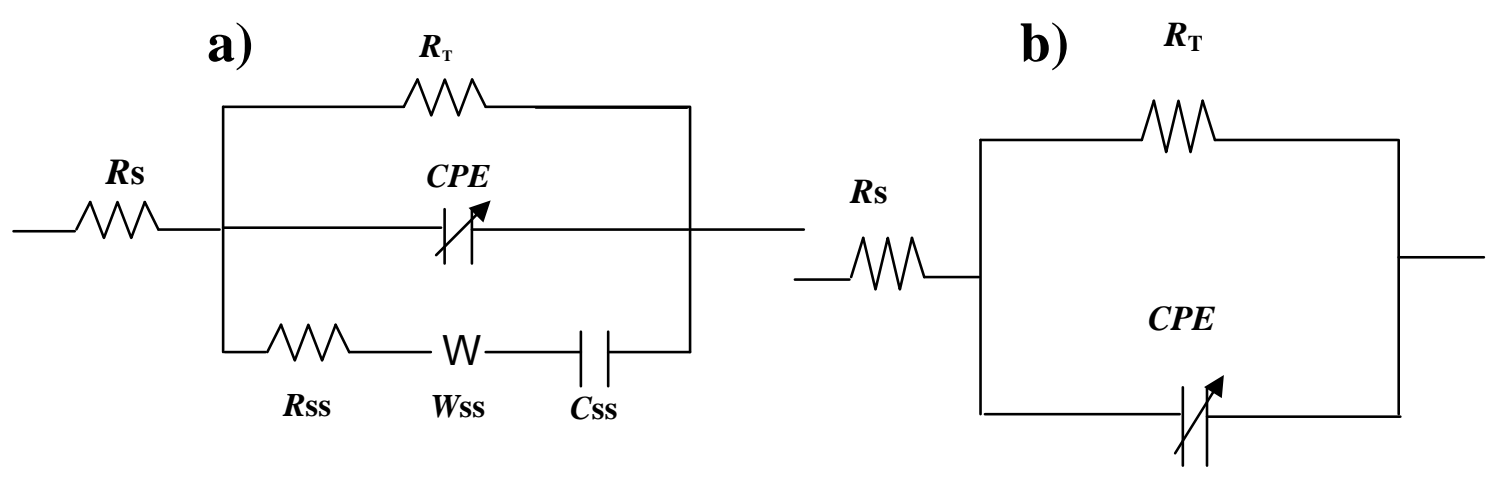


Fig 6
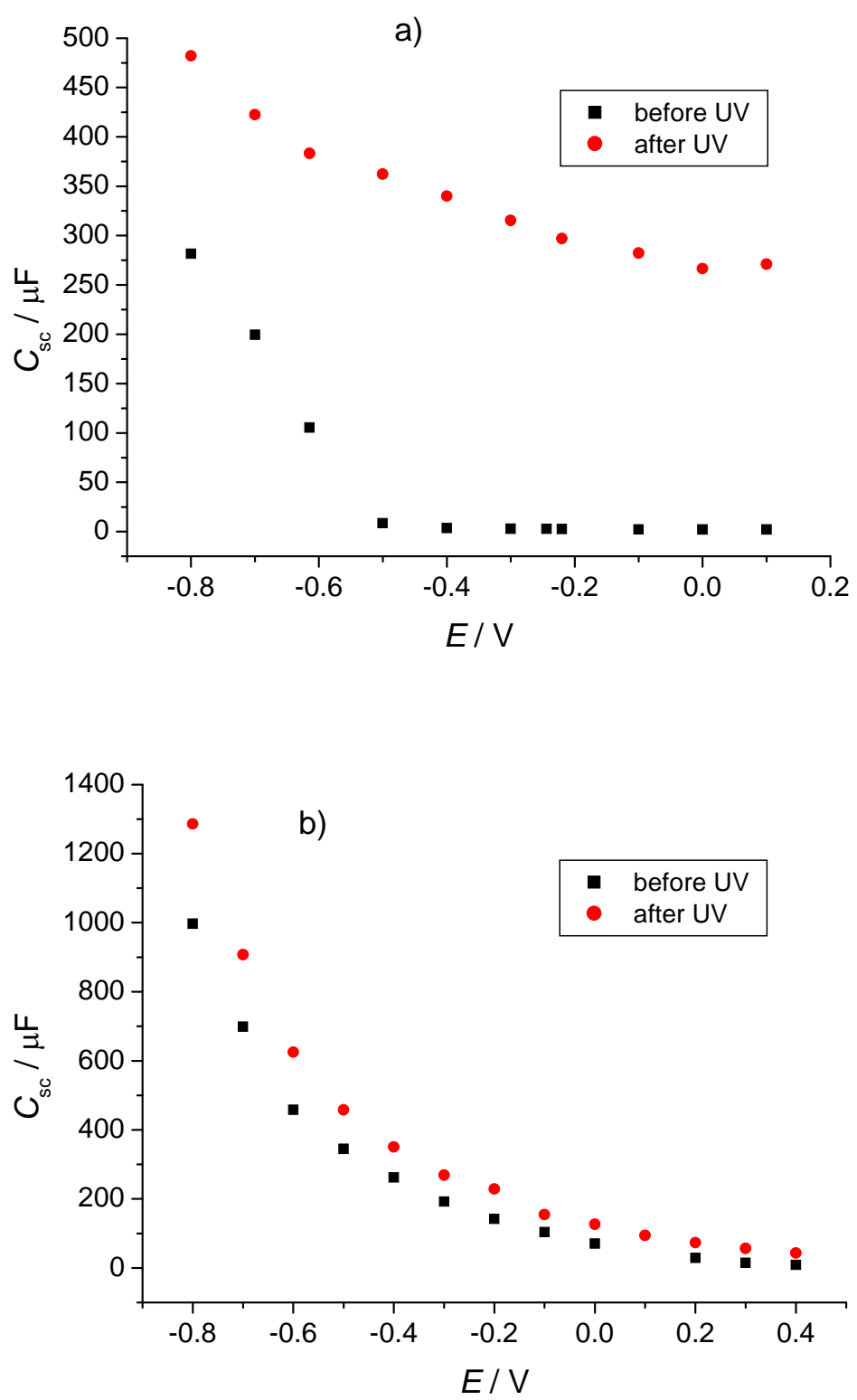
Fig 7

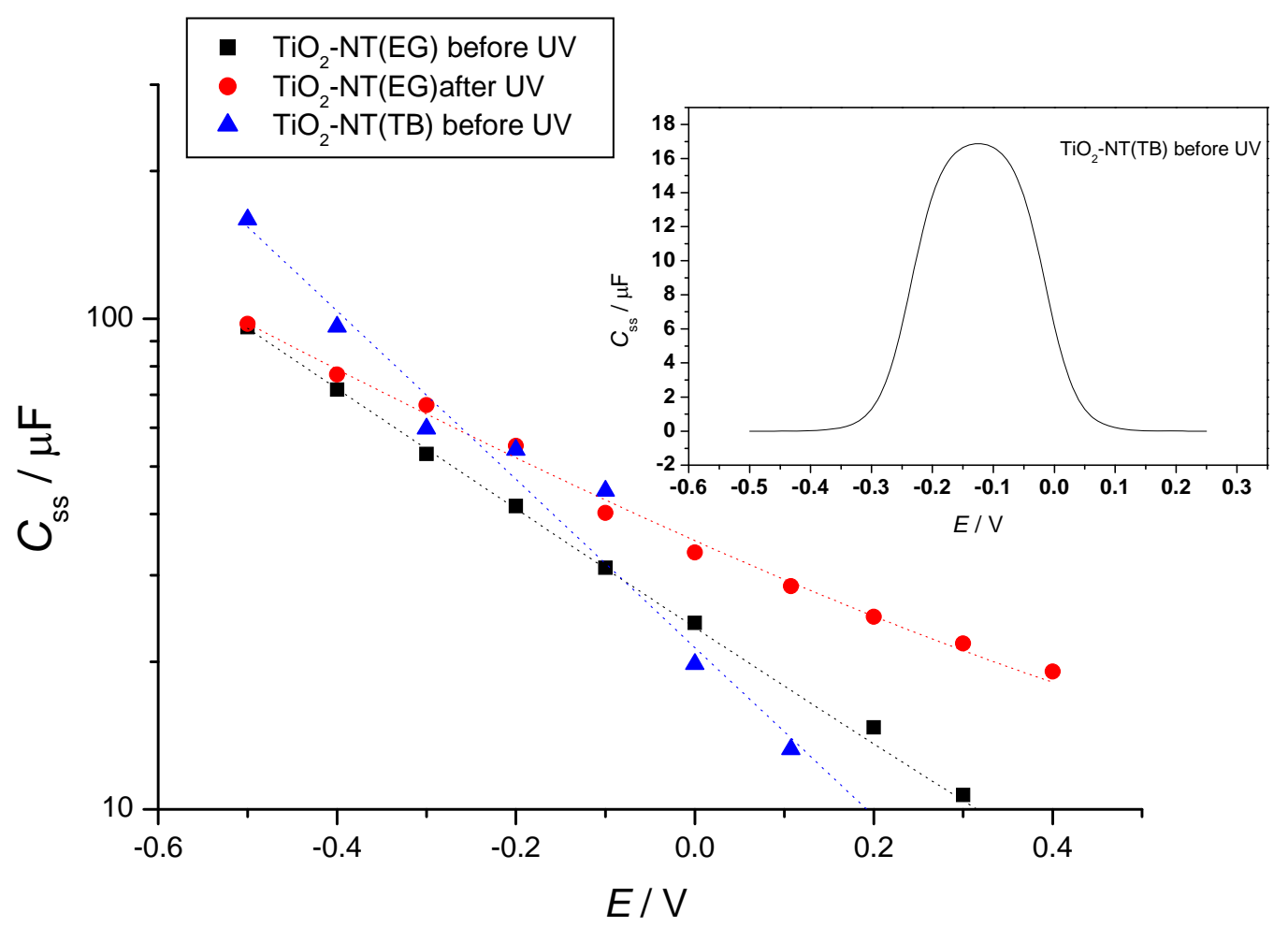


Fig. 8
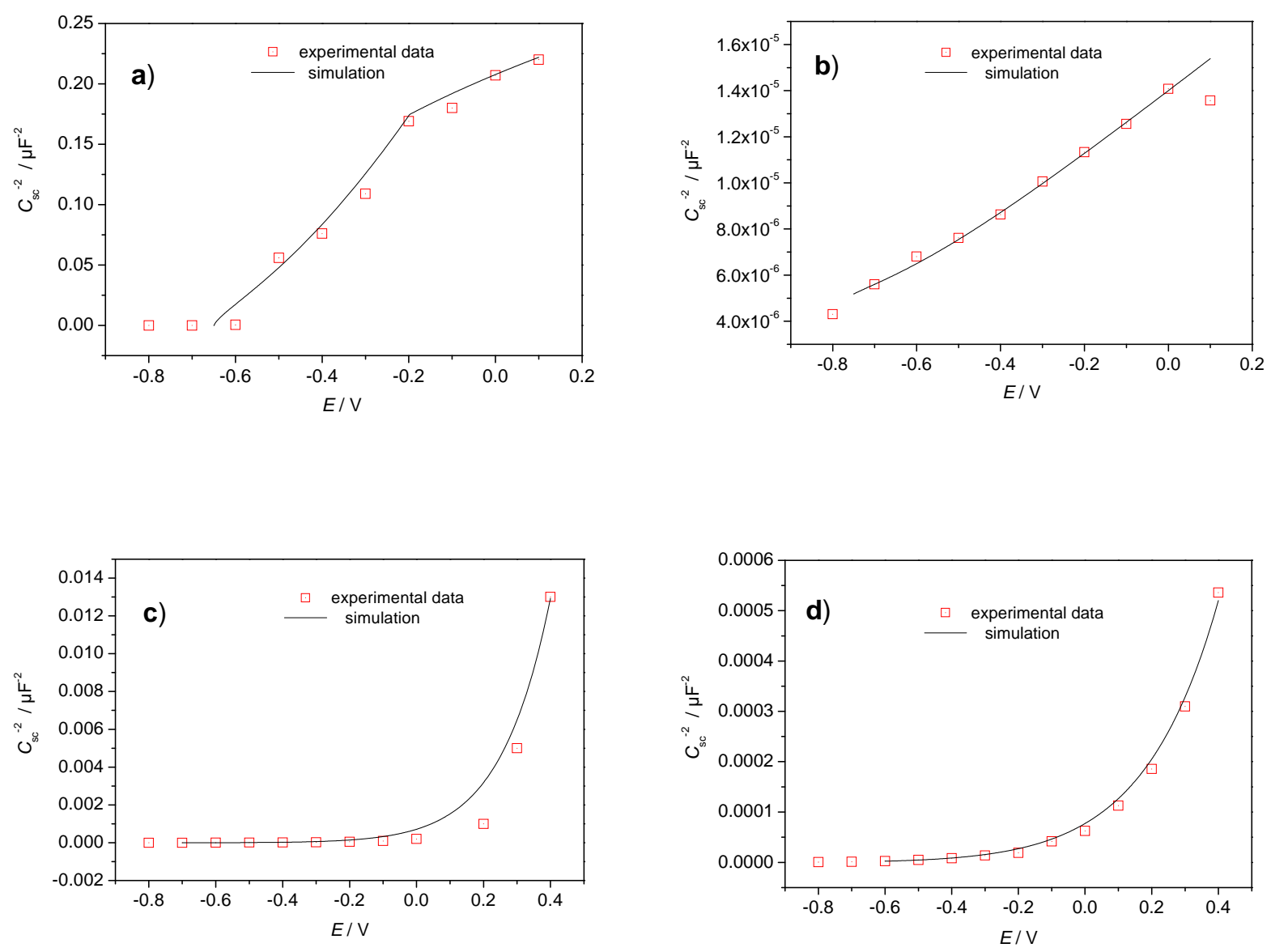
Fig 9
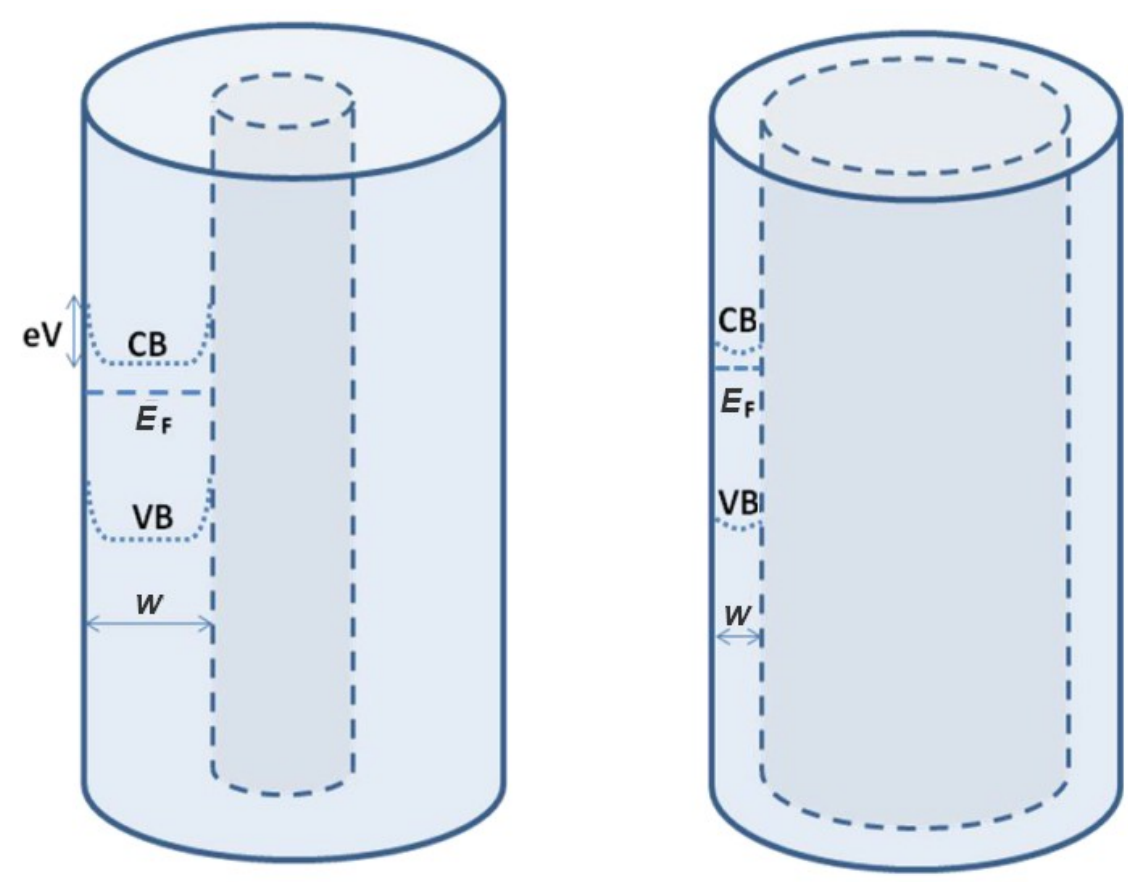